\title{
Quantification of Some Physico-Chemical Characteristics of Waste Water Effluent from Batu Tannery Industry at Different Batch, Addis Ababa, Ethiopia
}

Tadesu Hailu $^{1^{*}}$, Alemayehu Abebaw ${ }^{2}$ and Daniel Minilu ${ }^{3}$

${ }^{1}$ Department of Chemistry, Wolkite University, Ethiopia

${ }^{2}$ Department of Chemistry, Ambo University, Ethiopia

${ }^{3}$ Department of Chemistry, Hawassa University, Ethiopia

"Corresponding author: Hailu T, Department of Chemistry, Wolkite University, Ethiopia, Tel: +251115432311; E-mail: teklesilase@gmail.com

Received: August 28, 2018; Accepted: November 21, 2018; Published: December 05, 2018

Copyright: ( 2018 Hailu T, et al. This is an open-access article distributed under the terms of the Creative Commons Attribution License, which permits unrestricted use, distribution, and reproduction in any medium, provided the original author and source are credited.

\begin{abstract}
In the present study, the levels of selected heavy metals $(\mathrm{Cr}, \mathrm{Cd}, \mathrm{Mn}, \mathrm{Cu}, \mathrm{Zn}$, and $\mathrm{Pb})$ were determined using Flame Atomic Absorption Spectrophotometeric method. The following concentration ranges (mg/L) were recorded in wastewater samples: Cr (2.006-373.005), Cd (0.015-0.051), Mn (1.421-3.049), Cu (0.024-0.906) and Zn $(0.105-0.934)$. Whereas, $\mathrm{Pb}$ was found to be blow detection limit $(0.04)$. The concentration of $\mathrm{Cr}$ was highest followed by $\mathrm{Mn}$ in all sample sites and these values were found to be significantly higher than the maximum permissible limits of $\mathrm{WHO}, \mathrm{NEQS}$ and FEPA. The levels of $\mathrm{Cd}, \mathrm{Cu}$ and $\mathrm{Zn}$ were within the maximum permissible limits for effluent discharged into rivers. Decreasing in concentrations of heavy metals with distance from point source up to a distance of 40 meters was observed. $\mathrm{pH}$, Temperature $\left({ }^{\circ} \mathrm{C}\right), \mathrm{COD}, \mathrm{TDS}, \mathrm{TSS} \mathrm{SO}_{4}{ }^{2-}$ and $\mathrm{Cl}^{-}\left(\mathrm{mg}_{\mathrm{L}}\right)$ were also determined: Temperature (24.65-25.52), pH (8.85-10.31), SO ${ }^{2-}$ (22.74-695.77), TDS (1500.00-4300.00), TSS (1505.00-2498.33), $\mathrm{Cl}^{-}$(235.03-1396.29) and COD (512.39-902.50). Similarly, anion concentration decreased with distance from point source up to a distance of $40 \mathrm{~m}$. The control sample which is $40 \mathrm{~m}$ far before the wastewater inter into the Dufa River, recorded the lowest concentrations for all the parameters under studied. A statistical analysis of variance (ANOVA) at 95\% confidence level shows that, there is a statistical significance variation of means concentration between the four sampling sites except $\mathrm{pH}$ and temperature.
\end{abstract}

Keywords: Physicochemical pollutants; Tannery wastewater effluent; Dufa River; Flame atomic absorption spectrophotometer

\section{Introduction}

Environmental pollution is an undesirable change in hydrosphere and lithosphere. Advanced industrialization processes have provided comforts to human beings, on the other hand, but it has also resulted in indiscriminate release of gases and liquids, which polluted the environment of biological system. Now a day, large amount of untreated sewage/industrial water is being discharged in to surface bodies for disposal [1]. Industry has become integral part of modern society. As a result, production of waste is an inevitable of the industrial activities. A material is becoming waste when it is discharged without expecting to be compensated for its inherent value. Those wastes may pose a potential hazard to human and environment when improperly treated, stored, transported or disposed off or managed [2].

The discharge of industrial effluents, municipal sewage, farm and urban wastes carried by drains and channels to rivers worsen and broadens water pollution. High levels of pollutants in river water causes an increase in biological oxygen demand (BOD), chemical oxygen demand (COD), total dissolved solids (TDS), total suspended solids (TSS), toxic metals such as $\mathrm{Cd}, \mathrm{Cr}, \mathrm{Ni}$ and $\mathrm{Pb}$ and fecal coliform and hence make such water unsuitable for drinking, irrigation and aquatic life [3].
Tannery industry is one of the highly water intensive industries and large quantities of wastewater is discharged into water stream everyday and causing very serious environmental problems. Wastewater is any water that has been adversely affected in quality by anthropogenic influences. This wastewater may contain potentially hazardous heavy metals that adversely affect the environment and life in general $[4,5]$. Heavy metals are referred to as metallic elements (metal and metalloids) that have a high relative density and are toxic to aquatic biota and humans at low concentrations. They are conservative in nature, meaning they persist in the environment for long periods and deemed serious pollutants because of toxicity, persistence and nonbiodegradability in the environment. Certain heavy metals are important to human body at trace level but at higher levels they can be detrimental to health [6].

Manufacturing of leather, leather goods, leather boards and fur produces numerous byproducts, solid wastes, high amount of wastewater containing different loads of pollutants and emissions in to the air. The uncontrolled release of tannery wastewater effluents to natural water bodies or onto land increase health risk for human beings and environmental pollutants. Effluents from raw hide processing tanneries, which produce wetblue, crust leather or finished leather containing compounds of trivalent chromium $\mathrm{Cr}$ (III) and sulfides in most case which generate symptoms and diseases (e.g., nuasea, skin ulceration) to human [7].

In addition to the waste from different processes, the washing after different operations adds to the total volume of factory effluent to an appreciable extent. Soaking and pickling wastes contains high amount 
of sodium chloride while chrome tan liquor contains chromium. Although the exact quantity of water used varies widely between tanneries, a normal requirement was around 50-60 liters of water per kilogram of hide [8].

\section{Materials and Methods}

\section{Description of the study area}

The study was conducted inside the Batu tannery private limited company found in South of Addis Ababa at kality industrial zone, approximately $10 \mathrm{~km}$ away from the centre of Addis Ababa and it is near Walliya tannery industry. It is one of the largest tanneries in Ethiopia and built at a plot land of about $11,000 \mathrm{~m}^{2}$. The tannery produces various types of leather from sheep and goat skin and cattle hide. The industry is located to the riversides and its leather processing wastes join the water systems.

\section{Instrumentation and apparatus}

The following are lists of some major apparatuses that were used during field and laboratory experiment. pH/Ion-Meter, (WTW, Inolab Germany), weight balance, Hot air oven, FAAS (BUCK SCIENTIFIC MODEL 210 VGP (USA)), Spectrophotometer (UNICAM UV 300), mercury thermometer.

\section{Chemicals and reagents}

All chemicals and reagents used in this procedure were analytical grade (AR). 69 to $70 \%$ conc. $\mathrm{HNO}_{3}$ (Spectra, $\mathrm{BDH}$, England), Ferrous Ammonium Sulphate hydrated or Mohr salt $\left(\mathrm{Fe}\left(\mathrm{NH}_{3}\right)_{2}\left(\mathrm{SO}_{4}\right)_{2} \cdot 6 \mathrm{H}_{2} \mathrm{O}\right)$, distilled and deionized water, sulpheric acid (conc. $\mathrm{H}_{2} \mathrm{SO}_{4}$ ), silver nitrate $\left(\mathrm{AgNO}_{3}\right)$, mercuric sulphate $\left(\mathrm{Hg}_{2} \mathrm{SO}_{4}\right)$, potassium dichromate $\left(\mathrm{K}_{2} \mathrm{Cr}_{2} \mathrm{O}_{7}\right)$, potassium chromate $\left(\mathrm{K}_{2} \mathrm{CrO}_{4}\right)$, magnesium chloride $\left(\mathrm{MgCl}_{2} \cdot 6 \mathrm{H}_{2} \mathrm{O}\right)$, sodium acetate $\left(\mathrm{CH}_{3} \mathrm{COONa} \cdot 3 \mathrm{H}_{2} \mathrm{O}\right)$, acetic acid $\left(\mathrm{CH}_{3} \mathrm{COOH}\right)$, barium chloride $\left(\mathrm{BaCl}_{2}\right)$, sodium hydroxide $(\mathrm{NaOH})$, sodium sulphate $\left(\mathrm{Na}_{2} \mathrm{SO}_{4}\right)$, sodium chloride $(\mathrm{NaCl})$, potassium nitrate $\left(\mathrm{KNO}_{3}\right)$, stock and standard solutions of $\mathrm{Cr}, \mathrm{Cd}, \mathrm{Mn}, \mathrm{Pd}, \mathrm{Cu}$ and $\mathrm{Zn}$ were used $\left(1000 \mathrm{mg} / \mathrm{L}\right.$, PURO-GRAPHIC ${ }^{\mathrm{TM}}$ calibration standards, BUCK SCIENTIFIC), standard solution were used for the preparation of calibration curves for the determination of metals in the samples. Deionized water was used for cleaning of glassware and dilution of sample solutions.

\section{Procedures}

\section{Cleaning of apparatus}

Apparatus such as volumetric flasks, measuring cylinders, evaporating dishes, and digestion beakers and flasks were washed with non-ionic detergents and tap water, rinsed with deionized water. The digestion beakers and flasks and volumetric flasks were soaked with $10 \%$ (v/v) $\mathrm{HNO}_{3}$ for 24 hours followed by rinsing with deionized water, dried in oven and kept in dust free place until analysis begins. Prior to each use the apparatus were soaked and rinsed in deionized water.

\section{Statistical analysis}

Statistical analysis was performed with Statistical Package for Social Scientists (SPSS) 13.0, Microsoft Office Excel Program and Microcal
Origin 6.0 software. Mean, Standard deviation, list significance difference (LSD) and Analysis of Variance (ANOVA) were analyzed using SPSS 13.0 and Microsoft Office Excel Program. Depending upon the type and nature of results obtained, there are different statistical methods used to check whether there is a difference in results of analysis or not; and if there is a difference, statistical analysis will tell us the difference is significant. Of these, analysis of variance (ANOVA) is the best method. Analysis of variance (ANOVA) is used to test the hypothesis about the differences between three or more means [9]. The significance variation of the concentrations of the parameters in wastewater samples were tested at $p \geq 0.05$ levels. The significance variation of the four different batches (S1, S2, S3 and S4) was analyzed in order to examine mean distribution of the average concentration of the analyte along the sampling sites. Therefore, One-way ANOVA was used to test the variation in concentration at different sampling sites differ significantly or not and Least significant differences (LSD) was used to deciding the reason for the significant differences. Then Oneway ANOVA was adopted by assuming there is no statistical significant difference between the sampling points and there variations are coming from the same population (homogeneity of variance). The graphs were drawn using Microcal Origin 6.0 and figures were drawn using Microsoft Excel program software. The comparison between mean and standard deviation were performed $(\mathrm{p} \geq 0.05)$ at $95 \%$ confidence levels.

\section{Results}

The mean concentrations of metals $(\mathrm{Cr}, \mathrm{Cd}, \mathrm{Mn}, \mathrm{Cu}, \mathrm{Pd}$ and $\mathrm{Zn})$ are presented in Figures 1 and 2 (Table 1). This figure shows how the metals vary between the four sampling sites (S1, S2, S3 and S4) and at the same time compares the level of each metal at different sampling sites. The order of metal mean concentration is $\mathrm{Cr}>\mathrm{Mn}>\mathrm{Zn}>\mathrm{Cu}>\mathrm{Cd}$. Thus the concentration of $\mathrm{Cr}$ (2.007 to $373.005 \mathrm{mg} / \mathrm{L}), \mathrm{Mn}$ (1.421 to $3.049 \mathrm{mg} / \mathrm{L}), \mathrm{Zn}(0.105$ to $0.934 \mathrm{mg} / \mathrm{L}), \mathrm{Cu}(0.024$ to $0.906 \mathrm{mg} / \mathrm{L})$ and $\mathrm{Cd}(0.015$ to $0.050 \mathrm{mg} / \mathrm{L})$.

The recorded temperature of wastewater under investigation is $24.65 \pm 1.10^{\circ} \mathrm{C}$ to $25.22 \pm 1.33^{\circ} \mathrm{C}$ and $24.35 \pm 0.97^{\circ} \mathrm{C}$ for the control sample which were lower than WHO and FEPA standard of $30^{\circ} \mathrm{C}$ and NEQS standard of $40^{\circ} \mathrm{C}$. The levels of $\mathrm{pH}$ varied between $8.85 \pm 1.21$ and $10.31 \pm 1.19$ in the wastewater samples. Whereas, the $\mathrm{pH}$ value of the controlled sample is $8.71 \pm 0.53$.

The concentration of total suspended solids (TSS) is ranged from $1505.00 \pm 13.23 \mathrm{mg} / \mathrm{L}$ to $2498.33 \pm 7.64 \mathrm{mg} / \mathrm{L}$ and $1000.00 \pm 6.21 \mathrm{mg} / \mathrm{L}$ for the controlled sample (Table 2).

The average concentration of TDS is ranged $\mathrm{b} / \mathrm{n} 1500.00 \pm 10.00$ $\mathrm{mg} / \mathrm{L}$ to $4300.00 \pm 10.00 \mathrm{mg} / \mathrm{L}$ and $1300.00 \pm 12.00 \mathrm{mg} / \mathrm{L}$ for the controlled sample. The concentrations of sulphate in all the sampling points varied between $22.74 \pm 0.39$ to $695.77 \pm 6.96 \mathrm{mg} / \mathrm{L}$ (Table 1). High concentration of sulphate was observed in sample point S1, while low concentrations were observed for sample point S4. The concentration of the controlled sample was also $14.29 \pm 0.05 \mathrm{mg} / \mathrm{L}$.

The mean concentration of chloride is $235.03 \pm 11.97 \mathrm{mg} / \mathrm{L}$ to $1396.29 \pm 17.92 \mathrm{mg} / \mathrm{L}$ and $172.82 \pm 13.83 \mathrm{mg} / \mathrm{L}$ for the controlled. The high levels of $\mathrm{Cl}^{-}$concentration in the first two sampling points and in tannery. In the present study, the wastewater has an average COD concentration in the range of $255.39 \pm 5.54 \mathrm{mg} / \mathrm{L}$ to $902.50 \pm 6.54$ $\mathrm{mg} / \mathrm{L}$ and $81.09 \pm 5.34 \mathrm{mg} / \mathrm{L}$ for the controlled sample (Table 2). 
Citation: Hailu T, Abebaw A, Minilu D (2018) Quantification of Some Physico-Chemical Characteristics of Waste Water Effluent from Batu Tannery Industry at Different Batch, Addis Ababa, Ethiopia. J Environ Anal Toxicol 8: 592. doi:10.4172/2161-0525.1000592

Page 3 of 5

\begin{tabular}{|l|l|l|l|l|l|l|}
\hline \multirow{2}{*}{ Sampling Points } & \multicolumn{7}{|c|}{ Metal Concentration in $\mathbf{m g} / \mathbf{L}$} \\
\cline { 2 - 8 } & $\mathbf{C r}$ & $\mathbf{C d}$ & Mn & Pb & Zn & Cu \\
\hline S1 & $373.005 \pm 3.078$ & $0.050 \pm 0.002$ & $3.049 \pm 0.036$ & ND & $0.934 \pm 0.057$ & $0.906 \pm 0.036$ \\
\hline S2 & $168.310 \pm 6.319$ & $0.026 \pm 0.008$ & $2.964 \pm 0.007$ & ND & $0.604 \pm 0.007$ & $0.179 \pm 0.010$ \\
\hline S3 & $29.815 \pm 1.733$ & $0.015 \pm 0.003$ & $2.801 \pm 0.076$ & ND & $0.257 \pm 0.049$ & $0.153 \pm 0.009$ \\
\hline S4 & $2.006 \pm 0.058$ & $0.015 \pm 0.003$ & $1.421 \pm 0.051$ & ND & $0.105 \pm 0.013$ & $0.024 \pm 0.003$ \\
\hline Control & $0.549 \pm 0.026$ & $0.015 \pm 0.003$ & $1.249 \pm 0.476$ & ND & $0.085 \pm 0.001$ & $0.085 \pm 0.006$ \\
\hline Where: ND=Not Detected (concentration of the tested metal below the method detection limit (0.04)) & & & \\
\hline
\end{tabular}

Table 1: Mean of Concentration of Metals, Mean \pm SD $(n=3)$ in Wastewater Samples.

\begin{tabular}{|l|l|l|l|l|l|}
\hline \multirow{2}{*}{ Parameters } & \multicolumn{3}{|c|}{ Sampling Points } \\
\cline { 2 - 5 } & S1 & S2 & S3 & S4 \\
\hline Temp. & $25.22 \pm 1.33$ & $25.07 \pm 0.74$ & $24.88 \pm 1.05$ & $24.65 \pm 1.10$ \\
\hline $\mathrm{pH}$ & $10.31 \pm 1.19$ & $9.63 \pm 1.23$ & $9.54 \pm 1.07$ & $8.85 \pm 1.21$ & $24.35 \pm 0.97$ \\
\hline $\mathrm{COD}$ & $902.50 \pm 6.54$ & $832.66 \pm 3.64$ & $512.08 \pm 4.61$ & $255.39 \pm 5.54$ & $1500.00 \pm 10.00$ \\
\hline TDS & $4300.00 \pm 10.00$ & $3000.66 \pm 10.10$ & $2403.33 \pm 15.28$ & $151.09 \pm 5.34$ & $1300.00 \pm 12.00$ \\
\hline TSS & $2498.33 \pm 7.64$ & $2495.00 \pm 5.00$ & $1996.67 \pm 7.63$ & $1000.00 \pm 13.23$ \\
\hline SO ${ }_{4}^{2-}$ & $695.77 \pm 6.62$ & $68.58 \pm 0.12$ & $1342.31 \pm 9.84$ & $307.94 \pm 17.65$ & $22.74 \pm 0.39$ \\
\hline $\mathrm{Cl}^{2-}$ & $1396.29 \pm 17.92$ & $39.47 \pm 0.14$ & $235.03 \pm 11.97$ \\
\hline
\end{tabular}

Table 2: Mean \pm SD values of Physico-chemical Parameters $(\mathrm{mg} / \mathrm{L})$ except Temperature $\left({ }^{\circ} \mathrm{C}\right)$ and $\mathrm{pH}$ in Wastewater Samples.

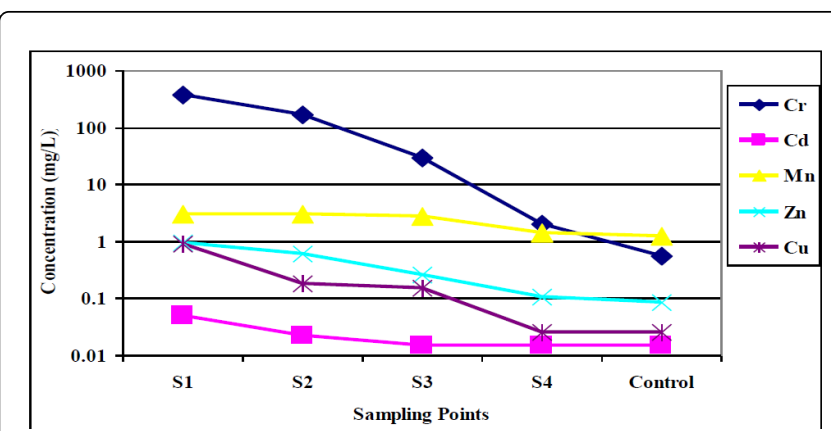

Figure 1: The mean Concentration of Heavy Metals in Tannery Wastewater Effluent at different Sampling point.

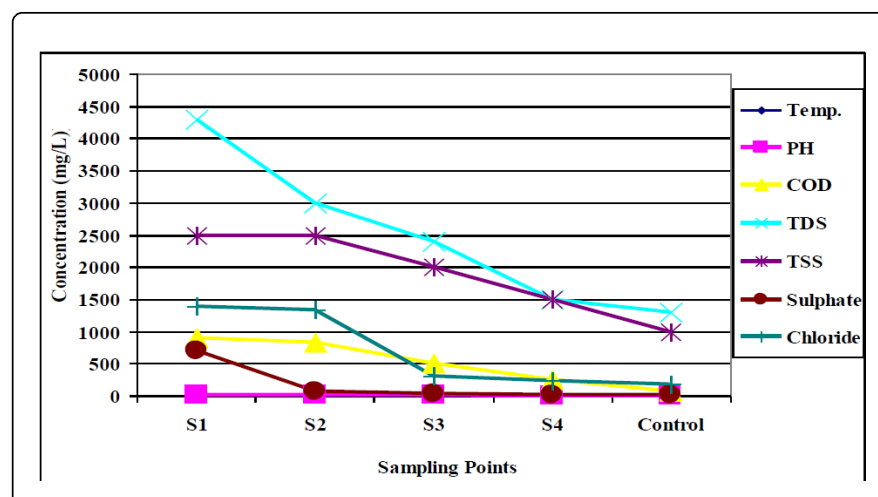

Figure 2: The mean Concentration of Physicochemical parameters in Tannery Wastewater Effluent at different Sampling point.

\section{Discussion}

The high concentration level of $\mathrm{Cr}$ is due to the use of much amount of chromium salt (chromium sulfate) during leather processing which is used for production of chromic compound, as well as dyestuff and pigment processes are not fixed, they are rejected or discharged in washed out effluents. This is because chromium possesses a low coefficient of friction, high hardness, good corrosion resistance, high heat resistance and anti-galling properties. In agreement with above 
observed data, the levels of all metals is small in the last site after the wastewater effluent were mixed with Dufa River.

The concentration of $\mathrm{Cr}$ at different sites were found to be higher than the maximum permissible limits for effluents discharged in to rivers set by FEPA (1991), WHO (2002) and NEQS (1991) of 1.0, 1.5 and $1.0 \mathrm{mg} / \mathrm{L}$ respectively and also the controlled sample with a concentration of $0.549 \mathrm{mg} / \mathrm{L}$, which was found below the maximum recommended limit values of FEPA, WHO and NEQS. In addition to $\mathrm{Cr}$, the mean concentrations of Mn were exceeds the FEPA and NEQS guide line value of 1.0 and $1.5 \mathrm{mg} / \mathrm{L}$ respectively, with a concentration of $1.249 \mathrm{mg} / \mathrm{L}$, which was found to be below the maximum recommended limit values of WHO $(1.5 \mathrm{mg} / \mathrm{L})$. On the other hand, the mean concentrations of $\mathrm{Cd}, \mathrm{Zn}$ and $\mathrm{Cu}$ in all the sampling points were below the maximum permissible limit set by FEPA, WHO and NEQS standards. This shows that $\mathrm{Cd}, \mathrm{Zn}$ and $\mathrm{Cu}$ do not contribute negative effect to the environment.

The mean $\mathrm{pH}$ values in all the sampling point were below the maximum permissible limit of 6-10 set by NEQS, except S1 which is above the maximum permissible limit. But according to WHO and FEPA maximum permissible tolerance limit (6.00-9.00) sample site $S 1$, S2 and S3 were found to be higher, while sample site S4 and the control one were found to be lower, for wastewater to be discharged into channels of river.

Literature classified wastewater TSS as follows: TSS less than 100 $\mathrm{mg} / \mathrm{L}$ as weak, TSS greater than $100 \mathrm{mg} / \mathrm{L}$ but less than $220 \mathrm{mg} / \mathrm{L}$ as medium and TSS greater than $220 \mathrm{mg} / \mathrm{L}$ as strong wastewater. Hence the results of the study show that wastewater effluent from Batu Tannery industry were classified as strong wastewater and cannot be discharged into stream. The highest TSS values in the industry was due to the water used for crushing processes that carries away the solid particles and increase the TSS level in the effluents. The mean concentration values of TSS obtained in all the sampling sites were extremely higher than the permissible limits set by NEQS $(200 \mathrm{mg} / \mathrm{L})$ and EEPA (30 mg/L).

The presence of high concentration of TDS may be originated from all stages of leather making; they comprise fine leather particles, residues from various chemical discharges and reagents from different waste liquors. The use of sodium chloride during the process of raw material preservation is a major contributor to high TDS levels in tannery wastewaters. According to the EEPA and NEQS standards $(3000 \mathrm{mg} / \mathrm{L}$ and $3500 \mathrm{mg} / \mathrm{L}$ respectively) the results of TDS in all sampling points including the controlled sample were below the maximum permissible limits except that of sample site $S 1$.

The high concentration of sulphate are not surprising because sulphate in the tannery effluent were emanating from the use of sulphuric acid used for batting (i.e., used for making the leather soft and flexible) or products with a high sodium sulphate used for diliming (i.e., for making the leather non-alkaline) content. The levels of sulphate concentrations were below the WHO limit of $250 \mathrm{mg} / \mathrm{L}$ and NEQS limit of $600 \mathrm{mg} / \mathrm{L}$ except sample site S1. On the other hand, all the concentrations of $\mathrm{SO}_{4}{ }^{2-}$ were above the FEPA permissible limits of $0.2 \mathrm{mg} / \mathrm{L}$ for the discharged of wastewater into river.

Wastewaters are due to use of sodium chloride $(\mathrm{NaCl})$ during the process of raw material (skin and hide) preservation. In addition to this, some sodium chloride $(\mathrm{NaCl})$ is also necessary for pickling procedures before tanning, soaking; liming-deliming, bating and degreasing also contribute to the high levels of chloride concentration. On the other hand, concentration values obtained for $\mathrm{Cl}^{-}$in $\mathrm{S} 1, \mathrm{~S} 2$ and
S3 sampling points were higher, while the values obtained in site S4 and the controlled sample were lower than WHO standard of 250 $\mathrm{mg} / \mathrm{L}$ for the discharged of wastewater into river water.

In addition to this, the $\mathrm{Cl}$ - values recorded in sample site $\mathrm{S} 1$ and S2 were above, while the values obtained in site S3, S4 and controlled samples were below the maximum permissible limits of NEQS standards (1000 mg/L).

High COD concentration observed in the wastewater might be due to the use of chemicals used for processing hides and skins, which are organic or inorganic that are oxygen demand in nature. An additional source of COD is the degreasing process (i.e., addition of degreasing agent to remove fat from the row hide).

The mean concentrations of COD in all the sampling point were higher than the NEQS values of $150 \mathrm{mg} / \mathrm{L}$ except the control sample, but all are lower than WHO values of $1000 \mathrm{mg} / \mathrm{L}$. On the other hand, according to EEPA the concentration of COD in all sampling points were higher except in S4 and the control sample.

\section{Conclusion}

The research generally found out that concentrations of heavy metals in wastewater samples are below allowable limits set by (FEPA, Nigeria), (WHO) and (NEQS, Pakistan) except that of $\mathrm{Cr}$ in all sampling points and $\mathrm{Mn}$ in the first three sampling points. The concentration of the physicochemical parameters as well as the heavy metals had shown a decreasing tendency along the wastewater treatment stages and channel. This will be an indication of the contamination decrease along the sampling stages and also as the distance of the wastewater channel increases from the point of discharge. The mean concentration of Chromium, Manganese, $\mathrm{Cl}^{-}$, COD and TSS levels should be strictly monitored by relevant authorities in order to prevent environmental pollution and reduce health hazard caused by pollution.

\section{Acknowledgements}

The author wish to thank Dr. Alemayehu Abebaw (advisor from Ambo University) and Ato Daniel Minilu (co-advisor from Hawassa University) for their faithful and immense advice, Chemistry Department staff members of Hawassa University, Batu Tannery industry, for their kind cooperation in facilitating conditions and resources throughout my study and the research was financed by Ministry of Education.

\section{References}

1. Lone MI, Saleem S, Mahmood T, Saifullah K, Hussain G (2003) Heavy metal contents of vegetables irrigated by sewage/tubewell water. Int J Agri Bio 5: 533-535.

2. Misra V, Pandey SD (2005) Hazardous waste, impact on health and environment for development of better waste management strategies in future in India. Environment International 31: 417-431.

3. Tariq M, Ali M, Shah Z (2006) Characteristics of industrial effluents and their possible impacts on quality of underground water. Soil Environ 25: 64-69.

4. Sulieman AM, Yousif AW, Mustafa AM (2010) Chemical, physicochemical and physical properties of wastewater from the Sudanese Fermentation Industry (SFI). In: Fourteenth International Water Technology Conference, pp: 305-315. 
Citation: Hailu T, Abebaw A, Minilu D (2018) Quantification of Some Physico-Chemical Characteristics of Waste Water Effluent from Batu Tannery Industry at Different Batch, Addis Ababa, Ethiopia. J Environ Anal Toxicol 8: 592. doi:10.4172/2161-0525.1000592

Page 5 of 5

5. Celik A, Kartal AA, Akdogan A, Kaska Y (2005) Determination of heavy metal pollution in Denizi. Environmental International, Turkey 31 105-112.

6. Yang H, Rose N (2005) Trace element pollution records in some UK lake sediments, their history, influence factors and regional differences. Environment International 31: 63-75.

7. Mashi SA, Alhassan MM (2007) Effects of wastewater discharge on heavy metals pollution in Fadama soils in Kano City, Nigeria. Biomedical and Environmental Sciences 20: 70-77.
8. Andrzej B, Koltuniewic Z (1997) Environmental commission of International Union of Leather Technologists and Chemists Societies (IULTCS). Typical pollution values related to conventional tannery processes, London, UK, p: 387.

9. Miller NJ, Mille CJ (2005) Statistical Chemometrics for Analytical Chemistry. 5th edn. Pearson Practice Hall, England, pp: 55-112. 